\title{
STUDY OF TRICHOMONAS VAGINALIS AND BACTERIAL VAGINOSIS IN PAP SMEAR AT A TERTIARY HEALTH CARE CENTRE OF NEPAL
}

\author{
Pathak $R,{ }^{1}$ Pradhan $P_{,}^{2}$ Pudasaini $S,{ }^{1}$ Maharjan $S,{ }^{1}$ Basnyat $A S^{3}$
}

${ }^{1}$ Department of Pathology, ${ }^{2}$ Department of Obstetrics and Gynecology, Nepal Medical College Teaching Hospital, Attarkhel, Gokarneshower-8, ${ }^{3}$ National Ayurveda Research and Training Center, Kirtipur, Kathmandu, Nepal

\begin{abstract}
Cervical-vaginal infections are common problems in women of reproductive age presented with clinical features like white vaginal discharge, foul smelling odor and pruritis. Trichomonas vaginalis, Candidia and Gardnerella vaginalis are responsible for infectious vaginitis in creating anaerobic environment favoring Bacterial vaginosis caused by organisms like Gardnerella vaginalis, Chlamydia Trachomatis. Papanicolaou (Pap) smear examination is the simple, quick, painless routine screening test used for identification and detection of precancerous changes of uterine cervix as well as the cervico-vaginal infections resulting from bacterial, fungal and candida infections. The prime objective of the study was to identify the age wise distribution of cervical-vaginal infections and determine the frequency of Trichomonas vaginalis (TV) and Bacterial vaginosis (BV). A descriptive cross-sectional study was carried out in the Department of Pathology, Nepal Medical College and Teaching Hospital, Kathmandu. A total of 163 cases of TV and BV diagnosed on Pap smear were taken for the study. However, 564 Pap smears were received in the Department of Pathology for cytological evaluation during the study period. Once the smears were stained, the presence of clue cells, cannon balls and Trichomonas were observed. Out of 564 Pap smears received during the study period, 163 cases were of BV, TV and combined BV and TV. These 163 cases were included in our study. The age ranged from 20 to 65 years with majority (19.1\%) of the women belonging to 35-39 years and the mean age was $38.18 \pm 10.18$ years. There were 97 cases $(17.2 \%)$ of BV, 50 cases $(8.9 \%)$ of TV and 16 cases $(2.8 \%)$ of $\mathrm{TV}$ and $\mathrm{BV}$ co-infection. Bacterial vaginosis was the most predominant type of cervicovaginal infection followed by TV infection and TV and BV co-infections. Trichomonas vaginalis may create an environment favoring the development of BV. Pap screening could be the beneficial tool in early disease diagnosis and helps in preventing further complications by starting appropriate treatment.
\end{abstract}

\section{KEYWORDS}

Bacterial vaginosis, Pap smear,

Trichomonas vaginalis infection,

\section{CORRESPONDING AUTHOR}

Dr. Rakesh Pathak

Assistant Professor,

Department of Pathology,

Nepal Medical College Teaching Hospital,

Attarkhel, Gokarneshower-8, Kathmandu, Nepal

Email: dr_rakesh@hotmail.com

Orcid ID: 0000-0003-0780-7416

DOI: https://doi.org/10.3126/nmcj.v22i1-2.29926 


\section{INTRODUCTION}

Cervical infections are the most commonly observed health issues in women of reproductive age group (15-49 years) that usually present with white vaginal discharge, foul smelling odor and pruritis. ${ }^{1}$ Trichomonas vaginalis (TV), Candidia and Gardnerella vaginalis are responsible for nearly $90 \%$ of diseases with infectious vaginitis. ${ }^{2}$ A flagellate protozoan, TV is sexually transmitted and helps in creating anaerobic environment favoring Bacterial vaginosis (BV) caused by organisms like Gardnerella vaginalis, Chlamydia trachomatis. ${ }^{3}$ Anaerobic bacteria are the most common agents that cause vaginitis/ vaginosis which lead to vulvo-vaginal candidiasis, BV and TV infection. ${ }^{4}$

Most of the bacteria-induced infections can easily be diagnosed by the Papanicolaou (Pap) smear examination. It is a simple, quick, painless routine screening test that is mostly used for identification and detection of precancerous dysplastic changes of uterine cervix as well as the cervico-vaginal infections resulting from bacterial, fungal and candida infections. ${ }^{5}$ In the case of Nepal, women living in mountainous and rural areas are mostly illiterate and are married at early age having limited access to health care and they are at particular risk of late diagnosis of cervical cancer and other cervico-vaginal infections with the peak incidence in the age group 45 to 65 years. ${ }^{6}$ The wide variety of pathogens cause cervical, vaginal and other infections resulting the identification of infectious agent more challenging. Physical examination of the patient, history and the appropriate tests like Pap smears are suggested for the effective diagnosis and treatment of such infections. $^{7}$

The objective of this study was to identify the spectrum of causative agents responsible for cervico-vaginal infections and determine the frequency of TV and BV in Pap smears received in the Department of Pathology at Nepal Medical College Teaching Hospital (NMCTH), Attarkhel, Gokarneshwor-8, Kathmandu.

\section{MATERIALS AND METHODS}

The present hospital based cross sectional study was carried out in the Department of Pathology, NMCTH, Kathmandu from September 2019 to December 2019. With the reference of study done by Vandana et al, ${ }^{8}$ the calculated sample size for the study was 95. However, 163 Pap smears with TV, BV and combined TV and BV coinfection were included out of 564 Pap smears received during the study period. Symptomatic, asymptomatic and pregnant women visiting Gynecology
Department were enrolled and screened with Pap smears. The Pap smear slides were fixed in 95\% ethanol for minimum of 15 minutes and sent to the Department of Pathology for cytopathological examination. The consent was taken in the Gynecology OPD before taking the Pap smear. Once the Pap smears were received in the Department of Pathology, they were checked for fixation and slides were stained by conventional method.

\section{Papanicolaou Method:}

After alcohol fixation, the smears were removed from fixative and rinsed in water. Then the smears were stained with Harris's Hematoxylin for 5 minutes, rinsed in water for 2 minutes and differentiated in $0.5 \%$ aqueous $\mathrm{HCl}$ for 10 seconds. These smears were rinsed in water, blued in Scott's water for 2 minutes and again rinsed in water for 2 minutes. Then the smears were dehydrated in $70 \%$ and $95 \%$ ethanol for 2 minutes each. Then the slides were stained in OG6 for 2 minutes and rinsed in 95\% alcohol for 2 minutes and stained in EA 50 for 3 minutes. Finally it was rinsed in 95\% alcohol for 1 minute before mounting.

These stained slides were examined under binocular microscope (Nikon Eclipse E200). The Bethesda system for reporting cervical pathology 2014 was followed for reporting. Besides diagnosing the intraepithelial lesions and carcinoma, presence of clue cells, cannon balls (pushballs polyballs) and filmy hazy background were noted. The diagnosis of shift in vaginal flora suggestive of BV was given if there were presence of clue cells (more than 20\%) and hazy background due to proliferation of coccobacilli. The coccobacilli were visualized as clumps of round cocci organism in Pap stain. Squamous cells covered by a layer of coccobacilli obscuring the cell membrane known as clue cells were observed. Filmy background was seen due to large numbers of coccobacilli.

Similarly, identification of one or more of the following morphological characters was considered conclusive for TV, pear-shaped, oval to round cyanophilic organism ranging in size from 15-30 microns; pale nucleus, vesicular, and centrally located with eosinophilic granular cytoplasmic. Few associated background changes like mature squamous cells with small perinuclear halo and 3-dimensional clusters of neutrophils (polyballs) were included.

\section{Statistical analysis:}

The data were entered in MS Excel 2016 and then analyzed statistically. The mean age and age wise distribution of TV, BV and combined TV and BV cases were found out. 


\section{RESULTS}

Out of 564 Pap smear samples received in the Department of Pathology, 163 (28.9\%) Pap smears were diagnosed with BV (Fig. 1), TV (Fig. 2) and TV and BV co-infection (Fig. 3). The patients were aged between 20 and 65 years, with mean age of $38.18 \pm 10.18$ years. Majority (19.1\%) of the women belonged to $35-39$ years.

Among 564 smears examined, 97 cases (17.2\%) had BV, 50 cases $(8.9 \%)$ had TV infection and 16 cases $(2.8 \%)$ had both types of infections (Table

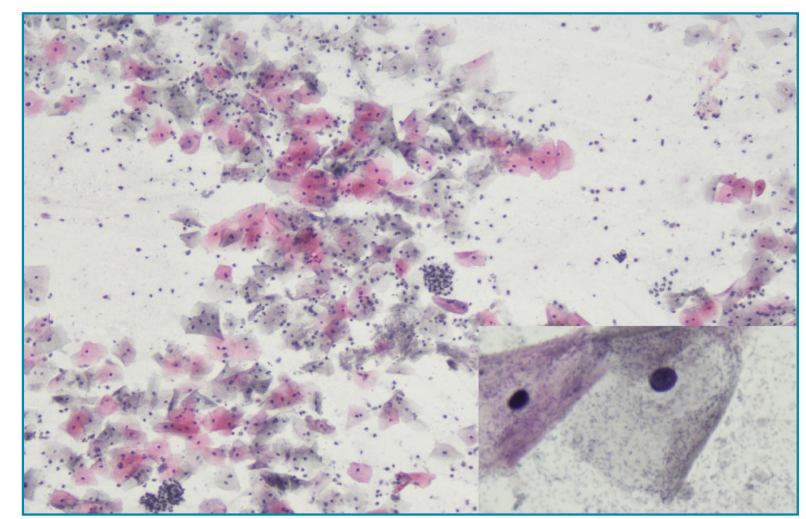

Fig.1: Bacterial vaginosis in Pap stain (20X). Inset shows clue cells (40X).

\begin{tabular}{|lc|}
\hline \multicolumn{2}{|c|}{ Table 1: Cytological diagnosis } \\
\hline Cytological diagnosis & $\mathbf{n}(\%)$ \\
Bacterial vaginosis (BV) & $97(17.2)$ \\
Trichomonas vaginalis (TV) & $50(8.9)$ \\
TV and BV & $16(2.8)$ \\
Others (NIELM and SIL) & $401(71.1)$ \\
Total & $\mathbf{5 6 4 ( 1 0 0 )}$ \\
\hline
\end{tabular}

1). Remaining 401 cases (71.1\%) were either Negative for intra epithelial lesion (NIELM) or Squamous intra epithelial lesion (SIL) and hence not included in our study. It was observed that $\mathrm{BV}$ was the most common infections followed by

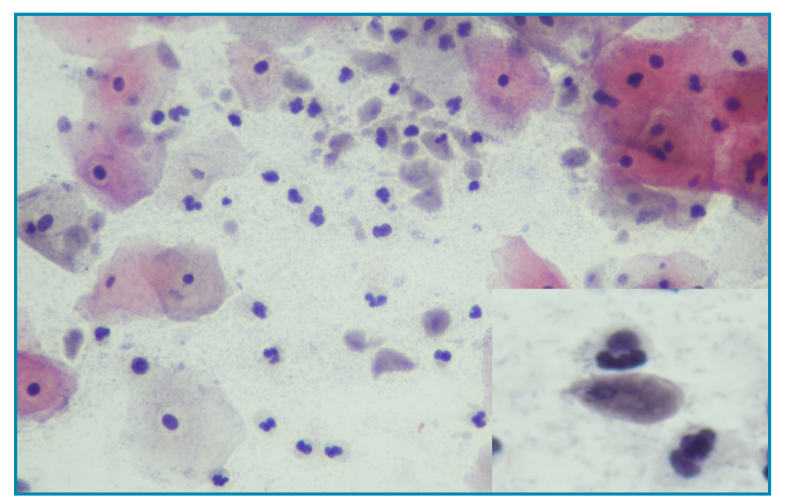

Fig. 2: Trichomonas vaginalis in Pap stain (40X). Inset shows pear shaped Trichomonas vaginalis (oil immersion)

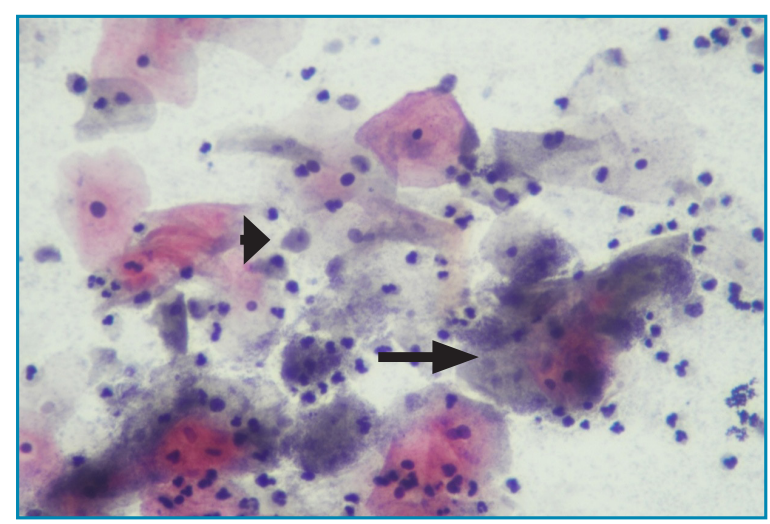

Fig. 3: Trichomonas vaginalis and Bacterial vaginosis (40x). Arrowhead revealing Trichomas vaginalis and Arrow revealing Clue cells of Bacterial vaginosis.

\section{Table 2: Age wise distribution of 163 Pap smears}

\begin{tabular}{|lcccc|}
\hline \multicolumn{5}{c|}{ Table 2: Age wise distribution of 163 Pap smears } \\
$\begin{array}{l}\text { Age Group } \\
\text { (Years) }\end{array}$ & $\begin{array}{c}\text { Findings on Pap Smear } \\
\text { Bacterial vaginosis } \\
\text { (BV) }\end{array}$ & $\begin{array}{c}\text { Trichomonas vaginalis } \\
\text { (TV) }\end{array}$ & Both BV and TV & n (\%) \\
$20-24$ & 6 & 8 & 0 & $14(8.6 \%)$ \\
$25-29$ & 13 & 8 & 1 & $22(13.5 \%)$ \\
$30-34$ & 14 & 7 & 5 & $26(15.9 \%)$ \\
$35-39$ & 20 & 10 & 1 & $31(19.1 \%)$ \\
$40-44$ & 19 & 5 & 1 & $25(15.3 \%)$ \\
$45-49$ & 10 & 5 & 4 & $19(11.7 \%)$ \\
$50-54$ & 9 & 4 & 3 & $16(9.8 \%)$ \\
$55-59$ & 3 & 2 & 1 & $6(3.7 \%)$ \\
$\geq 60$ & 3 & 1 & 0 & $4(2.4 \%)$ \\
Total & $\mathbf{9 7}$ & $\mathbf{5 0}$ & $\mathbf{1 6}$ & $\mathbf{1 6 3}(\mathbf{1 0 0 \% )}$ \\
\hline
\end{tabular}


TV infections. Women of reproductive age group (15-49 years) were mostly infected by cervical related infections.

Maximum number of Pap smears was received from the females of age group 35-39 years. Similarly, the maximum number of BV and TV infections was also observed in the same age group. The second most common age group affected was 30-34 years (Table 2).

\section{DISCUSSION}

Cervical infectionis the most common problem faced by young and sexually active women. Pap smear is the commonly used screening technique for diagnosing precancerous or cancerous lesions as well as cervico-vaginal infections. ${ }^{1,5}$

There were 163 cases of cervicovaginal infection including BV, TV and combined BV and TV coinfection in our study. Bacterial vaginosis was the commonest cervicovaginal infection seen followed by TV infection. Similar finding was seen in a study done by Vandana et $a l^{8}$ where BV was the commonest infection and the commonest cause of vaginal discharge. A study done by Mittal et $a l^{9}$ reported $12 \%$ prevalence of BV which was less when compared to our study. It was stated that the early diagnosis of BV can easily prevent complications especially in pregnant women by starting appropriate treatment in his study.

A study done in Cameroon, by Kamga et a ${ }^{10}$ also showed the high prevalence of BV among pregnant women. Sodhani et $a^{11}$ also observed $41.5 \%$ prevalence of BV including both symptomatic and asymptomatic patients.

In our study, maximum number of patients of TV and BV were in the age group of 30-39 years and co-infection (BV and TV) in the age group 3034 years. In contrast to our study, Kumar et $a l^{5}$ in his study done in Northern part of India, the maximum number of coinfection was observed in the age group 41-50 years however TV infection was seen in age group 31-40 years. Vandhana et $a l^{8}$ found that maximum number cases (54\%) of $\mathrm{BV}$ were seen among the women of reproductive age group (20-30 years). In another study done by Vardar et $a l^{12}$ it was found that BV infection was mostly associated with complications like premature rupture of membranes, endometritis and preterm delivery.

Trichomonous vaginalis was the second most common (8.9\%) type of infections observed in our study. Our study correlates well with the finding of studies done by Bukhari et $a l^{1}$ and Cheraghi et $a l^{3}$ where TV was the reason for symptomatic and asymptomatic infection related to female urogenital system. A study conducted by De Glehn et al ${ }^{13}$ also identified the high prevalence of TV infection among the samples studied and the infection was positively associated with the number of life time sex partners.Similarly, Malkappa et $a l^{14}$ and Brooks-Smith-lowe et $a l^{15}$ also reported the higher incidence of TV infection.

Co-infection (BV and TV) is also one of the common finding which we come across in our daily practice. Kumar et $a l^{5}$ found higher incidence of co infection in his study. But there were only $2.8 \%$ cases of co infection in our study. A study by Gatski et $a l^{16}$ reported that TV and $\mathrm{BV}$ are the common infections found in human immunodeficiency virus (HIV) positive women. It was also suggested that infection with TV may create an environment favoring the development of BV.

The important complication of BV as cervical dysplasia was explained by Tokyol et $a l^{17}$ and it was hypothesized that BV could be important in developing cervical neoplasia. In this condition, abnormal microflora produce carcinogenic nitrosamins which can lead to carinoma.

In conclusion, cervicovaginal infections was found to be highest in the sexually active women of reproductive age group (15-49) years. Bacterial vaginosis was the most predominant type of infections observed. Although hygiene behaviors, socio-demographic and clinical status play the important role in such infections, routine Pap smear examination plays a significant role in identification of $\mathrm{TV}$ and $\mathrm{BV}$ in majority of women. The Pap screening could be beneficial in early disease diagnosis and also helps in preventing further complications by commencing appropriate treatment.

\section{REFERENCES}

1. Bukhari $\mathrm{MH}$, Majeed $\mathrm{M}$, Qamar Se et al.Clinicopathological study of Papanicolaou (Pap) smears for diagnosing of cervical infections. Diagn Cytopathol 2010; 40: 35-41.

2. Adad SJ, de Lima RV, Sawan ZT et al. Frequency of Trichomonas vaginalis, Candida $\mathrm{sp}$ and
Gardenerellavaginalis in cervical-vaginal smears in four different decades. Sao Paulo Med J 2001; 119: 200-5.

3. Cheraghi M, Zahra R, Parsa S. Prevalence of cervical-vaginal infections in the pap-smear samples in Iran. Glob J Health Sci 2014; 6: 201-6. 
4. Sobel J. Vaginitis, vulvitis, cervitis and cutaneous vulval lesions. In: Cohen J, Powderly WG, editors. Infectious diseases. $2^{\text {nd }}$ Ed. Spain: Elsevier Ltd: 2004.p.683-91.

5. Kumar N, Singh P, Rudra S. Papanicolaou smear as a tool for detection of cervico-vaginal infections in a rural tertiary care centre of Northern India: Retrospective analysis. Ind J Obstet Gynecol Res 2016; 3: 343-7.

6. Thapa N, Shrestha G, Maharjan M et al. Burden of cervical neoplasia in mid-western rural Nepal: a population-based study. J Gynecol Oncol 2018; 29: $1-11$.

7. Sivaranjini R, Jaisankar TJ, Thappa DM, Kumari R, Chandrasekhar L. spectrum of vaginal discharge in a tertiary care setting. Trop Parasitol 2013; 3: 13540.

8. Vandana G, Kumar R, Khan S, Anil S. Cytological findings of bacterial vaginosis in routine Pap smears. IOSR-J Dent Med Sci 2018; 179: 68-78.

9. Mittal V, Jain A, Pradeep Y. Development of modified diagnostic criteria for bacterial vaginosis at peripheral health centres in developing countries. J Infect Dev Ctries 2012; 6: 373-7.

10. Kamga YM, Ngunde JP, Akoachere JFKT. Prevalence of bacterial vaginosis and associated risk factors in pregnant women receiving antenatal care at the Kumba Health District (KHD), Cameroon. BMC Preg Childbirth 2019; 19: 1-8.
11. Sodhani P, Garg S, Bhalla P, Singh MM, Sharma S, Gupta S. Prevalence of Bacterial vaginosis in a community setting and role of the pap smear in its detection. Acta Cytol 2005; 49: 634-8.

12. Vardar E, Maral I, Inal M, Ozguder O, Tasli F, Postaci. Comparison of Gram stain and Pap smear procedures in the diagnosis of bacterial vaginosis. Infect Dis Obstet Gynecol 2002; 10: 203-7

13. De Glehn MP, Ferreira Sa LCE, da Silva HDF, Machado ER. Prevalence of Trichomonas vaginalis in women of reproductive age at a family health clinic. J Infect Dev Ctries 2017; 11: 269-76.

14. Malkappa SK, Surpam RB, Chakraverti TK. Pap smear for screening T. vaginalis. J Evolution Med Dent Sci 2012; 1: 837-40.

15. Brooks-Smith-Lowe K, Rodrigo S. Prevalence of Bacterial vaginosis in Grenadian women of reproductive age. West Ind Med J 2013; 62: 599-603.

16. Gatski M, martin DH, Clark RA, Harville E, Schmidt N, Kissinger P. Co-occurrence of Trichomonas vaginalis and Bacterial vaginosis among HIVpositive women. Sex Transm Dis 2011; 38: 163-6.

17. Tokyol C, Aktepe OC, Cevrioglu AS, Altindis M, Dilek FH. Bacterial vaginosis: Comparison of Pap smear and microbiological test results. Mod Pathol 2004; 17: 857-60. 